\title{
SEASON AND LANDSCAPE ELEMENT WISE CHANGES IN THE COMMUNITY STRUCTURE OF AVIFAUNA OF TAMHINI, NORTHERN WESTERN GHATS, INDIA
}

\author{
Anand D. Padhye ${ }^{1}$, Mandar Paingankar ${ }^{2}$, Neelesh Dahanukar ${ }^{3}$ and Satish Pande ${ }^{4}$ \\ ${ }^{1}$ Department of Zoology, Abasaheb Garware College, Karve Road, Pune, Maharashtra 411004, India \\ ${ }^{2}$ Department of Zoology, University of Pune, Pune, Maharashtra 411007, India \\ ${ }^{3}$ Indian Institute of Science Education and Research, 900 NCL Innovation Park, Dr. Homi Bhabha Road, Pune, Maharashtra 411008, India \\ ${ }^{4}$ Ela Foundation, C-9, Bhosale Park, Sahakar Nagar-2, Pune, Maharashtra 411009, India \\ Email: ${ }^{1}$ adpadhye@yahoo.co.uk
}

\begin{abstract}
The biological resources of the Western Ghats are under threat due to deforestation and other anthropogenic activities. As monitoring and mapping the biodiversity is the first step in the systematic conservation planning, our study takes the initial step of documenting avifaunal diversity and distribution along the seasonal gradient and across five landscape elements. We monitored bird community in Tamhini, northern Western Ghats, across six seasons and five landscape elements using line transect method for two years. The data were analysed for a and b diversity. Maximum a diversity was reported in early winter, spring and summer. Disturbed areas with human interference showed maximum diversity. Season wise analysis revealed high b diversity, while in landscape element wise it was comparatively less. Our analysis suggests that the avifauna of Tamhini shows highly dynamic population changes, which could be attributed to north-south migration, local migration, breeding seasons, vegetation changes, food availability and availability of water. Our findings in the seasonal and landscape wise distribution of avifauna are important with respect to monitoring animal diversity and defining conservation strategies in the northern Western Ghats.
\end{abstract}

KEYWORDS

Western Ghats, Avifauna, Bird diversity, Community structure, Landscape wise distribution, Seasonal distribution.

Owing to their high level of endemism in vertebrate and plant species, Western Ghats of India is considered as one of the 25 hotspots of biodiversity recognized globally (Myers et al., 2000). Nonetheless, its biodiversity is under threat due to deforestation (Myers, 1990; Jha et al., 2000). This decline in the biological resources of the Western Ghats is of immediate concern because of two reasons: firstly, they harbour even greater amounts of evolutionary history than expected by species numbers alone (Sechrest et al., 2002), and secondly, the accelerating and potentially catastrophic loss of biotic diversity is unlike any other environmental threat, as it is irreversible (Mittermeier et al., 1998). Understanding this immediate concern, Western Ghats Biodiversity Network (WGBN) organised a program of sampling species level diversity in number of taxa from 25 different localities distributed over the length of Western Ghats (Gadgil, 1996), so as to design and implement potent conservation strategies. This study is a part of the same program.

Unlike most other animal taxa, study on birds offer a number of attractive features. Firstly, birds have been studied extensively, so a lot of information on biology, distribution and ecology is accessible. As good field guides (Ali, 1996; Pande, 2003) are available, birds can be identified in the field, with accuracy, without employing any destructive techniques. Also, there are fewer chances of taxonomic uncertainties. However, the taxon was studied for various qualitative aspects during early period of the bird studies, and the trend of quantitative studies revealing good statistical data to support qualitative aspects has emerged only recently (Daniels et al., 1990; 1992; Pramod et al., 1997a; Pramod et al., 1997b).

Gole (1998) studied the avifauna of northern Western Ghats. He had monitored avifauna of 10 localities between $16^{\circ}-19^{\circ} \mathrm{N} \& 73^{\circ}-74^{\circ} \mathrm{E}$. In this study emphasis was given on the qualitative aspects including the preferences for the forest types, altitudinal ranges and food habits.

In the present study we have explored the diversity and distribution of avifauna in Tamhini, northern Western Ghats. We studied the distribution pattern and diversity of birds across seasonal gradient in five different landscape elements. We also studied the dynamics in distribution of avifauna so that our findings will also aid help in design good conservation strategies.

\section{Study site}

Tamhini $\left(18^{\circ} 27^{\prime} \mathrm{N} \& 73^{\circ} 25^{\prime} \mathrm{E}\right)$, Taluka Mulshi, district Pune, is a small village situated on the crest line of northern Western Ghats (Fig. 1). The average altitude of the village and its surrounding area is $600 \mathrm{~m}$, while the surrounding hilltops have altitudes ranging from 850 to $1050 \mathrm{~m}$. The $25 \mathrm{~km}^{2}$ area, that we monitored totally, includes four other small villages namely Nivewadi, Sarole, Dhangarwadi and Dongarwadi. Some part of the study area, especially around the villages, is a private farmland. Some mountain slopes bear reserved forests conserved by the Maharashtra State Forest Department. Climatic conditions of this area are typically tropical. The dense forest areas are humid throughout the year where the relative humidity ranges between $70 \%$ in summer to almost $100 \%$ in monsoon. The yearly rainfall is around 5500 to $6500 \mathrm{~mm}$. Average minimum and maximum temperature range between $15^{\circ}-25^{\circ} \mathrm{C}$. The minimum temperature sometimes drops to even less than $10^{\circ} \mathrm{C}$ while the maximum shoots up to $30^{\circ} \mathrm{C}$.

Manuscript 1706; @ ZOO; Date of publication 21 August 2007 Received 10 January 2007; Revised received 18 July 2007; Finally accepted 27 July 2007 


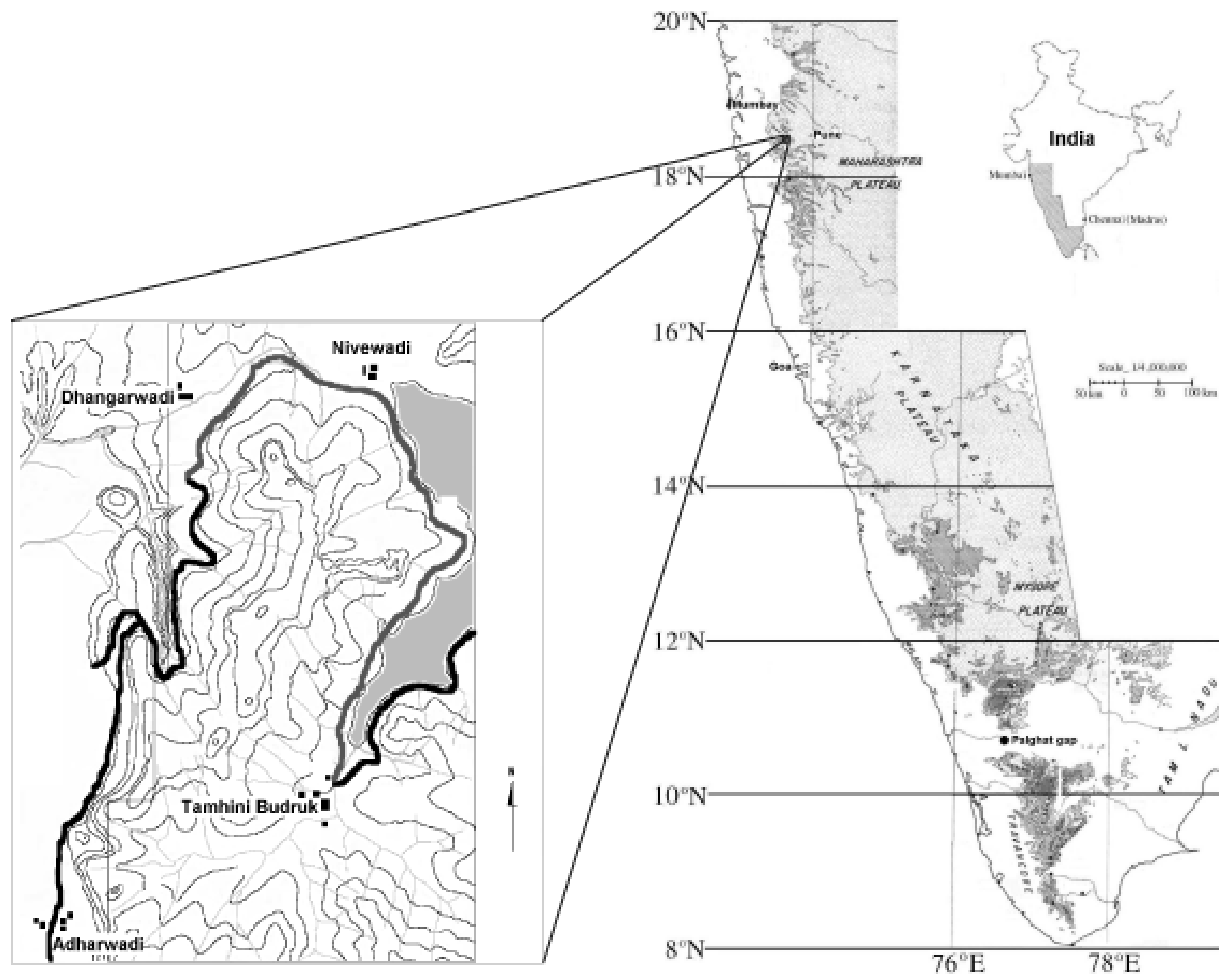

Figure 1. Map of study area

\section{Methodology}

\section{Data collection}

Six line transects were set up, which were approximately $500 \mathrm{~m}$ in length and $10 \mathrm{~m}$ in width, passing through the five landscape element types. The transect line was walked at a constant pace for approximately half-an-hour. Observations were taken between 0730 and $1100 \mathrm{hr}$, depending on the season, when birds were most active. Transects were worked every month from October 1998 to September 2000. Birds were identified in situ with the help of a field guide (Ali, 1996). For the interpretation of collected data the year was divided into six seasons: (i) Spring - February and March, (ii) Summer April and May, (iii) Early monsoon - June and July, (iv) Late monsoon - August and September, (v) Early winter - October and November, (vi) Late winter - December and January. Furthermore, each transect line was also categorised in one of the five landscape elements, viz. evergreen canopy (LSE 1); Ragi shift cultivation (scrubland subjected to slash and burn activity) (LSE 2); riparian (LSE 3); grassland (LSE 4) and
Paddy field with human habitation (LSE 5). The population fluctuation in bird species across seasons and across landscape elements was studied by preparing simple matrix with species in column and season or landscape elements in row (Appendix 1).

\section{Data analysis}

In order to estimate the total number of species that could be present in the study area, in the given season, and in each LSE type, we constructed species individual curves using data gathered through transects. Cumulative number of species recorded was plotted against the number of individuals seen. We fitted Michelis-Menten equation, given by $\mathrm{S}=\mathrm{S}_{\max } \mathrm{N} /$ $\left(K_{m}+\mathrm{N}\right)$ where, $\mathrm{S}$ is the cumulative number of species, $\mathrm{N}$ is the number of individuals, $\mathrm{S}_{\max }$ is the maximum number of species that could be present and $\mathrm{K}_{\mathrm{m}}$ is the Michelis-Menten constant (Paranjape \& Gore, 1997).

Margalef's species richness index was used to compare species richness across seasons and across landscape elements. The index is calculated using the equation $\mathrm{R}=(\mathrm{S}-1) / \ln \mathrm{N}$, 
Table 1. Checklist of birds and their seasonal and LSE wise distribution

\begin{tabular}{|c|c|c|c|c|c|c|c|c|c|c|c|c|c|}
\hline \multirow{2}{*}{$\begin{array}{l}\text { Common name* } \\
\text { Babbler, Jungle }\end{array}$} & \multirow{2}{*}{$\begin{array}{l}\text { Scientific name* } \\
\text { Turdoides striatus }\end{array}$} & \multicolumn{6}{|c|}{ Season } & \multicolumn{5}{|c|}{ LSE type } & $\%$ Abundance \\
\hline & & $\mathrm{Sp}$ & Su & $\mathrm{Em}$ & $\mathrm{Lm}$ & Ew & Lw & - & 2 & - & - & - & 3.0973 \\
\hline Babbler, Quaker Tit & Alcippe poioicephala & Sp & - & - & $\mathrm{Lm}$ & Ew & - & - & 2 & - & - & - & 0.9027 \\
\hline Babbler, Rufus Bellied & Dumetia hyperythra & Sp & - & - & - & - & - & - & 2 & - & - & - & 0.1396 \\
\hline Babbler, Indian Scimitar & Pomatorhinus horsfieldii & - & Su & - & - & Ew & - & - & - & 3 & - & - & 0.4257 \\
\hline Babbler, Spotted & Pellorneum ruficeps & - & Su & - & $\mathrm{Lm}$ & - & - & - & 2 & - & - & - & 0.2347 \\
\hline Barbet, Coppersmith & Megalaima haemacephala & - & Su & - & - & - & - & - & - & - & 4 & - & 0.1394 \\
\hline Barbet, Brown-headed & Megalaima zeylanica & Sp & Su & $\mathrm{Em}$ & - & Ew & $L w$ & - & 2 & - & - & - & 6.3417 \\
\hline Barbet, White-cheeked & Megalaima viridis & - & Su & - & $\mathrm{Lm}$ & Ew & - & - & - & 3 & - & - & 0.7119 \\
\hline Bee-eater, Small & Merops orientalis & Sp & Su & - & - & Ew & $L w$ & - & 2 & - & - & - & 2.5249 \\
\hline Blackbird, Eurasian & Turdus merula & Sp & Su & Em & - & - & Lw & - & - & - & 4 & - & 1.9524 \\
\hline Bluebird, Asian Fairy & Irena puella & Sp & - & - & - & - & - & - & - & - & 4 & - & 0.1396 \\
\hline Bulbul, Black & Hypsipetes leucocephalus & - & Su & - & - & - & - & - & - & 3 & - & - & 0.2348 \\
\hline Bulbul, Red-vented & Pycnonotus cafer & Sp & Su & $\mathrm{Em}$ & $\mathrm{Lm}$ & Ew & $L W$ & - & 2 & - & - & - & 10.1585 \\
\hline Bulbul, Red-whiskered & Pycnonotus jocosus & Sp & Su & Em & $\mathrm{Lm}$ & Ew & Lw & - & 2 & - & - & - & 8.2501 \\
\hline Bulbul, White-browed & Pycnonotus luteolus & - & - & - & - & - & $\mathrm{LW}$ & 1 & - & - & - & - & 0.1394 \\
\hline Bulbul, Yellow-browed & Iole indica & Sp & - & - & - & - & - & - & - & - & - & 5 & 0.2348 \\
\hline Bushchat, Pied & Saxicola caprata & Sp & Su & Em & - & Ew & $L w$ & - & 2 & - & - & - & 1.2845 \\
\hline Coucal, Greater & Centropus sinensis & Sp & Su & - & $\mathrm{Lm}$ & - & - & - & 2 & - & - & - & 0.3303 \\
\hline Crow, House & Corvus splendens & Sp & Su & - & - & Ew & - & - & 2 & - & - & - & 0.3303 \\
\hline Crow, Jungle & Corvus macrorhynchos & Sp & Su & $\mathrm{Em}$ & $\mathrm{Lm}$ & Ew & - & - & 2 & - & - & - & 3.9562 \\
\hline Dove, Little Brown & Streptopelia senegalensis & - & Su & - & - & - & - & 1 & - & - & - & - & 0.1394 \\
\hline Dove, Red Collared & Streptopelia tranquebarica & Sp & Su & Em & - & Ew & $\mathrm{LW}$ & - & - & - & 4 & - & 5.3875 \\
\hline Dove, Spotted & Streptopelia chinenesis & Sp & Su & - & - & Ew & - & - & - & 3 & - & 5 & 0.8074 \\
\hline Drongo, Black & Dicrurus macrocercus & Sp & - & - & - & Ew & - & - & 2 & - & - & - & 1.3798 \\
\hline Eagle, Creasted Serpent & Spilornis cheela & Sp & - & - & - & Ew & - & - & - & 3 & - & 5 & 1.1889 \\
\hline Egret, Cattle & Bubulcus ibis & Sp & - & - & - & Ew & - & - & - & - & 4 & - & 1.4753 \\
\hline Flowerpecker, Tickell's & Dicaeum erythrorynchos & $\mathrm{Sp}$ & Su & - & - & Ew & - & - & - & - & - & 5 & 1.2845 \\
\hline Flycatcher, Asian Paradise & Terpsiphone paradisi & $\mathrm{Sp}$ & - & - & - & Ew & $\mathrm{Lw}$ & - & - & - & - & 5 & 1.0936 \\
\hline Flycatcher, White-bellied Blue & Cyornis pallipes & - & - & - & - & Ew & - & - & 2 & - & - & - & 0.1394 \\
\hline Francolin, Painted & Francolinus pictus & Sp & Su & - & - & Ew & LW & - & 2 & 3 & - & - & 1.6661 \\
\hline Junglefowl, Grey & Gallus sonneratii & $\mathrm{Sp}$ & Su & - & - & - & - & - & - & - & - & 5 & 2.0478 \\
\hline Harrier, Montagu's & Circus pygargus & - & - & - & - & - & LW & - & 2 & - & - & 5 & 0.1394 \\
\hline Heron, Indian Pond & Ardeola grayii & Sp & - & - & - & - & - & - & 2 & - & - & 5 & 0.1394 \\
\hline Iora, Common & Aegithina tiphia & Sp & Su & Em & $\mathrm{Lm}$ & Ew & - & 1 & 2 & - & 4 & - & 2.0478 \\
\hline Kingfisher, Storkbilled & Halcyon capensis & - & - & - & - & Ew & - & - & - & - & 4 & - & 0.1394 \\
\hline Kingfisher, Lesser Pied & Ceryle rudis & - & - & - & - & Ew & $L w$ & - & - & - & 4 & 5 & 0.4257 \\
\hline Kingfisher, Small Blue & Alcedo atthis & - & - & - & - & Ew & $L w$ & 1 & - & - & - & 5 & 0.5211 \\
\hline Kingfisher, White-breasted & Halcyon smyrnensis & Sp & Su & Em & - & Ew & Lw & - & 2 & - & - & - & 0.5211 \\
\hline Kite, Black-shouldered & Elanus caeruleus & - & Su & - & - & - & - & - & 2 & - & 4 & - & 0.1394 \\
\hline Koel, Asian & Eudynamys scolopacea & - & Su & - & - & Ew & - & 1 & 2 & - & - & - & 0.2347 \\
\hline Lapwing, Red-wattled & Vanellus indicus & - & - & $\mathrm{Em}$ & - & - & - & - & 2 & - & 4 & 5 & 0.1394 \\
\hline Lark, Malabar Crested & Galerida malabarica & - & - & - & - & Ew & - & - & - & 3 & - & - & 0.2347 \\
\hline Martin, Dusky Crag & Hirundo concolor & $\mathrm{Sp}$ & - & - & - & - & $L w$ & - & 2 & 3 & - & - & 0.7118 \\
\hline Minivet, Scarlet & Pericrocotus flammeus & $\mathrm{Sp}$ & Su & - & - & Ew & - & - & 2 & 3 & 4 & 5 & 0.4257 \\
\hline Moorhen, Common & Gallinula chloropus & - & - & - & - & Ew & - & 1 & - & 3 & - & 5 & 0.1394 \\
\hline Munia, Spotted & Lonchura punctulata & Sp & - & - & - & - & - & 1 & 2 & - & 4 & 5 & 0.6165 \\
\hline Myna, Common & Acridotheres tristis & $\mathrm{Sp}$ & - & - & - & - & - & 1 & - & - & 4 & 5 & 0.1394 \\
\hline Oriole, Black-naped & Oriolus chinensis & $\mathrm{Sp}$ & - & - & - & - & - & - & 2 & - & - & 5 & 0.1394 \\
\hline Parakeet, Plum-headed & Psittacula cyanocephala & $\mathrm{Sp}$ & - & - & - & - & - & 1 & - & 3 & - & - & 0.2348 \\
\hline Parakeet, Rose-ringed & Psittacula krameri & $\mathrm{Sp}$ & Su & - & - & - & - & - & - & - & - & 5 & 0.3303 \\
\hline Pigeon, Blue Rock & Columba livia & Sp & - & - & - & - & - & 1 & 2 & - & 4 & 5 & 0.1394 \\
\hline Prinia, Ashy & Prinia socialis & $\mathrm{Sp}$ & - & - & - & Ew & - & 1 & 2 & 3 & 4 & 5 & 0.4257 \\
\hline Prinia, Franklin's & Prinia hodgsonii & $\mathrm{Sp}$ & - & - & - & - & - & 1 & 2 & 3 & 4 & 5 & 0.1394 \\
\hline Quail, Common & Coturnix coturnix & Sp & - & - & - & - & - & - & 2 & - & 4 & 5 & 0.3303 \\
\hline Robin, Indian & Saxicoloides fulicata & $\mathrm{Sp}$ & Su & Em & - & Ew & $L w$ & 1 & 2 & 3 & 4 & 5 & 2.0478 \\
\hline Robin, Oriental Magpie & Copsychus saluaris & Sp & Su & $\mathrm{Em}$ & - & Ew & $\mathrm{LW}$ & 1 & 2 & 3 & 4 & - & 0.8074 \\
\hline Rosefinch, Common & Carpodacus erythrinus & - & - & - & - & Ew & - & 1 & - & 3 & - & - & 0.2348 \\
\hline Shikra & Accipiter badius & $\mathrm{Sp}$ & - & - & - & - & - & 1 & 2 & 3 & - & 5 & 0.3303 \\
\hline Shrike, Southern Grey & Lanius meridionalis & Sp & - & - & - & - & - & 1 & 2 & 3 & 4 & - & 0.1394 \\
\hline Shrike, Rufus-backed & Lanius schach & Sp & Su & - & $\mathrm{Lm}$ & Ew & Lw & 1 & 2 & - & 4 & 5 & 5.4828 \\
\hline Starling, Brahminy & Sturnus pagodarum & - & Su & - & - & - & - & 1 & - & - & 4 & - & 0.2348 \\
\hline Sunbird, Purple & Nectarinia asiatica & $\mathrm{Sp}$ & Su & $\mathrm{Em}$ & - & Ew & $L w$ & 1 & 2 & 3 & - & 5 & 16.1699 \\
\hline Sunbird, Purple-rumped & Nectarinia zeylonica & - & - & - & - & Ew & LW & - & 2 & 3 & - & - & 0.2347 \\
\hline Sunbird, Small & Nectarinia minima & - & - & - & - & Ew & - & 1 & 2 & 3 & 4 & - & 0.1394 \\
\hline Swallow, Wire-tailed & Hirundo smithii & $\mathrm{Sp}$ & - & - & - & - & - & 1 & 2 & 3 & 4 & 5 & 1.0936 \\
\hline Swift, Alpine & Tachymarptis melba & Sp & - & - & - & - & - & 1 & 2 & 3 & 4 & 5 & 0.6165 \\
\hline Swift, House & Apus affinis & Sp & - & - & - & - & - & 1 & 2 & - & 4 & 5 & 0.4257 \\
\hline Tailor Bird, Common & Orthotomus sutorius & Sp & - & $\mathrm{Em}$ & - & - & - & 1 & 2 & 3 & 4 & 5 & 0.4257 \\
\hline Vulture, Long-billed & Gyps indicus & Sp & Su & - & - & Ew & - & - & 2 & 3 & 4 & - & 3.0973 \\
\hline Wagtail, Forest & Dendronanthus indicus & - & - & - & - & - & $L w$ & 1 & 2 & - & - & 5 & 0.7118 \\
\hline Wagtail, Grey & Motacilla cinerea & - & - & $\mathrm{Em}$ & - & - & - & - & - & - & - & 5 & 0.1393 \\
\hline Wagtail, White & Motacilla alba & - & - & - & - & Ew & - & 1 & 2 & 3 & 4 & 5 & 0.1393 \\
\hline Wagtail, Yellow & Motacilla flava & - & - & Em & - & - & - & 1 & 2 & 3 & 4 & 5 & 0.1394 \\
\hline Warbler, Blyth's Reed & Acrocephalus dumetorum & - & - & - & - & Ew & - & 1 & 2 & 3 & 4 & 5 & 0.4256 \\
\hline Warbler, Greenish Leaf & Phylloscopus trochiloides & - & - & - & - & - & Lw & 1 & 2 & 3 & 4 & 5 & 0.1394 \\
\hline Weaver, Baya & Ploceus philippinus & - & - & - & - & Ew & - & 1 & 2 & 3 & 4 & 5 & 0.2347 \\
\hline
\end{tabular}


Table 2. Checklist of birds observed out of the transects within the study area

\begin{tabular}{ll}
\hline Common name* & Scientific Name* \\
\hline Bunting, Crested & Melophus lathami \\
Cuckoo, Pied Crested & Clamator jacobinus \\
Cormorant, Little & Phalacrocorax niger \\
Dove, Ring & Streptopelia decaocto \\
Eagle-owl, Rock & Bubo bengalensis \\
Egret, Little & Egretta garzetta \\
Fantail Flycatcher, White-browed & Rhipidura aureola \\
Hornbill, Malabar Pied & Anthracocerous coronatus \\
Kite, Black & Milvus migrans govinda \\
Malkoha, Small Green-billed & Phoenicophaeus viridirostris \\
Minivet, Small & Pericrocotus cinnamomeus \\
Myna, Jungle & Acridotheres fuscus \\
Oriole, Golden & Oriolus oriolus \\
Pitta, Indian & Pitta brachyura \\
Sandpiper, Common & Actitis hypoleucos \\
Sparrow, House & Passer domesticus \\
Swallow, Red-rumped & Hirundo daurica \\
Tern, River & Sterna aurantia \\
Thrush, Malabar Whistling & Myiophonus horsfieldii \\
Tit, Grey & Parus major \\
Tree pie, Indian & Dendrocitta vagabunda \\
Vulture, Indian White-backed & Gyps bengalensis \\
Wagtail, Large Pied & Motacilla maderaspatensis \\
Waterhen, White-brested & Amaurornis phoenicurus \\
Whiteeye, Oriental & Zosterops palpebrosus \\
Woodpecker, Yellow-fronted Pied & Dendrocopus mahrattensis \\
\hline &
\end{tabular}

* All common and scientific names in Appendix I and II are as per Mankadan and Pittie (2002)

where $\mathrm{S}$ is the number of species, $\mathrm{N}$ is the total number of individuals (Magurran, 1988).

The $\alpha$-diversity of bird species across seasons and across landscape element was calculated using Shannon index of diversity given by the equation, $\mathrm{H}^{\prime}=-\Sigma \mathrm{p}_{\mathrm{i}} \ln \mathrm{p}$

where, $\mathrm{p}_{\mathrm{i}}=\mathrm{n}_{\mathrm{i}} / \mathrm{N} ; \mathrm{n}_{\mathrm{i}}$ is the number of individuals of $\mathrm{i}^{\text {th }}$ species; and $\mathrm{N}=\Sigma \mathrm{n}_{\mathrm{i}}$ (Magurran, 1988).

To calculate whether species are distributed evenly across seasons and across landscape elements, evenness index was used which is given by the equation, $\mathrm{E}=\mathrm{H}^{\prime} / \ln \mathrm{S}$ (Magurran, 1988).

The $\beta$-diversity, which represents unshared species, was measured by finding similarity or overlap between bird species composition across seasons and across LSE types, using Bray Curtis similarity index (McAleece, 1998). Dendrograms were prepared to understand seasonal and LSE wise trends.

Randomised blocks ANOVA was used to compare the difference between Shannon and Richness index across seasons and across months. The significance of pair wise differences in the mean Shannon and Richness index was calculated using two-tailed t-test.

\section{Results}

In the transect sampling we could record 78 bird species. However, from model fitted to species accumulation curve, the $\mathrm{S}_{\max }$ estimate suggests that there could be at least 90 species in the study area. The total checklist, which also includes bird species encountered outside the transects, shows 91 species (Tables 1 \& 2) indicating the appropriate sampling efforts. The percentage abundance of each species in transects is given in Table 1. The most abundant species was Purple Sunbird followed by Red-vented Bulbul. The species abundance curve

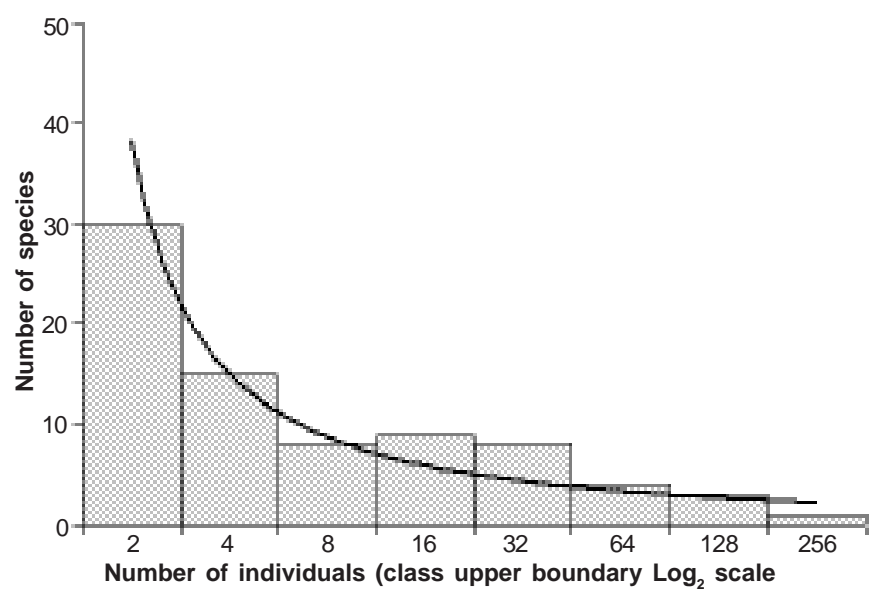

Figure 2. Species abundance curve. Note the higher number of rare species
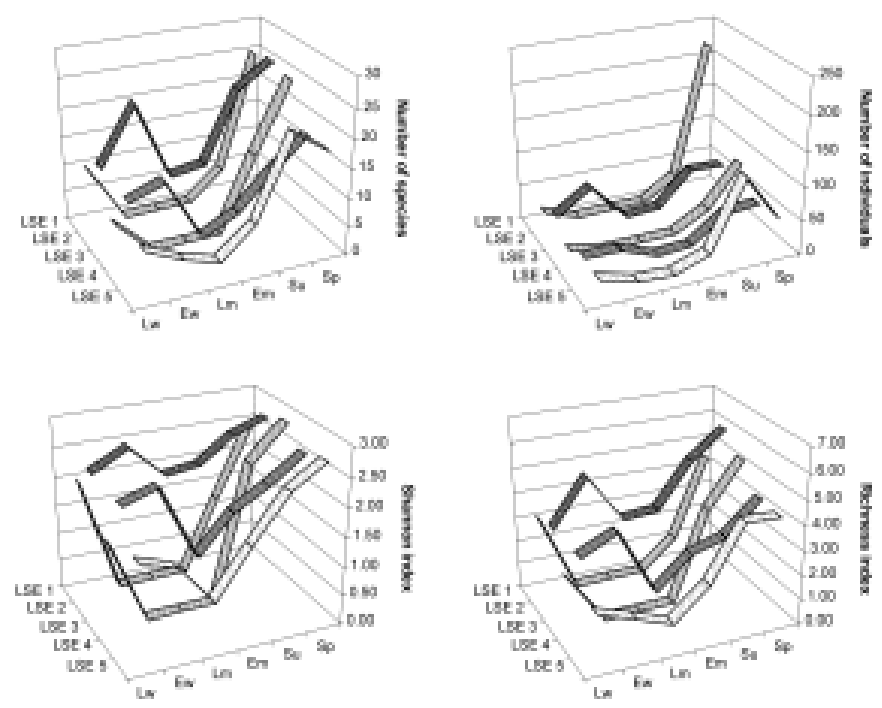

Figure 3. Three-dimensional ribbon plots depicting change in the number of species, number of individuals, Shannon index and Richness index across five LSE types and six seasons. LSE types are as per Table 2. Seasons are Sp - Spring; Su - Summer; Em - Early monsoon; Lm - Late monsoon; Ew - Early winter; Lw - Late winter

(Fig. 2) showed a $\log$ series distribution where the number of rare species (frequency of occurrence $\leq 16$ ) is more $(82 \%)$ and the number of abundant species (frequency of occurrence $>$ $8)$ is less $(18 \%)$. This indicates an uneven species distribution.

Maximum species were found in spring followed by early winter, while maximum individuals were found in spring followed by summer (Table 3). Maximum Richness index and unique species were found in spring followed by early winter. Shannon diversity index was maximum in early winter followed by spring. Number of species, individuals, unique species, Richness index and Shannon diversity index were minimum in late monsoon; however, the Evenness index was maximum in late monsoon. 
Table 3. Seasonal variation in species abundance, uniqueness, expected maximum number of species $\left(S_{\max }\right)$, Richness index, Shannon index and Evenness index

\begin{tabular}{llllllll}
\hline Season & Species & Individuals & Unique * & $\mathbf{S}_{\max }{ }^{*}$ & Richness & Shannon & Evenness \\
\hline Spring & 49 & 433 & 8 & 69.48 & 7.9068 & 3.0581 & 0.7858 \\
Summer & 39 & 286 & 3 & 39.66 & 6.7185 & 2.8004 & 0.7644 \\
Early Monsoon & 17 & 60 & 3 & 27.04 & 3.9078 & 2.3130 & 0.8164 \\
Late Monsoon & 10 & 31 & 0 & 31.57 & 2.6209 & 2.0648 & 0.8967 \\
Early Winter & 41 & 166 & 5 & 60.00 & 7.8247 & 3.1089 & 0.8372 \\
Late Winter & 23 & 72 & 3 & 41.00 & 5.1442 & 2.7115 & 0.8648 \\
\hline
\end{tabular}

* - Number of species observed only in the concerned season; \# - Predicted from Michaelis-Mentan Equation

Table 4. Landscape element wise variation in species abundance, uniqueness, expected maximum number of species ( $\left.S_{\text {max }}\right)$, Richness index, Shannon index and Evenness index. LSE types are stream bank with evergreen canopy (LSE 1); Ragi shift cultivation - scrubland subjected to slash and burn activity (LSE 2); stream bank without canopy cover (LSE 3); grassland (LSE 4) and Human habitation, paddy field and scrubland (LSE 5)

\begin{tabular}{llllllll}
\hline Landscape element & Species & Individuals & Unique* & $\mathbf{S}_{\max }{ }^{*}$ & Richness & Shannon & Evenness \\
\hline LSE1 & 32 & 256 & 3 & 56.46 & 5.5904 & 2.5796 & 0.7443 \\
LSE2 & 50 & 260 & 15 & 72.88 & 8.8119 & 3.2457 & 0.8297 \\
LSE3 & 31 & 126 & 4 & 63.80 & 6.2031 & 3.1318 & 0.9120 \\
LSE4 & 34 & 148 & 6 & 52.73 & 6.6037 & 3.0349 & 0.8606 \\
LSE5 & 37 & 247 & 6 & 77.62 & 6.5343 & 2.9061 & 0.8048 \\
\hline
\end{tabular}

* - Number of species observed only in the concerned LSE type; * Predicted from Michaelis-Mentan Equation

Table 2 depicts that maximum number of species, individuals and unique species were found in LSE2. Nonetheless, there was a marginal difference in number of individuals of LSE 1, 2 and 5. Richness index and Shannon diversity index was maximum in LSE 2 and minimum in LSE 1. The Evenness index was maximum in LSE 3. The comparison of LSE 1 and LSE 3, both of which were stream bank transects with and without canopy cover respectively, suggests that both yield approximately equal number of total species and unique species, however, LSE 1 showed more number of individuals than LSE 3. Richness index, Shannon diversity index and Evenness index of LSE 3 were more than LSE 1.

Three-dimensional ribbon plots depicting change in the number of species, number of individuals, Shannon index and Richness index across five LSE types and six seasons are given in Fig. 3. Change in number of species across seasons shows similar trends for LSE 1 and LSE 3. LSE 2 shows maximum number of species in any given season. In spring, maximum number of individuals was seen in LSE 1, while in early winter it was LSE 2 and in summer it was LSE 5. Shannon diversity index and Richness index were more consistent in LSE 2 followed by LSE 4, while it showed high shifts in LSE 1, 3 and 5. Shannon and Richness indices change significantly across seasons $(\mathrm{F}=7.95$ and $8.23, p=0.0003$ and 0.0004 respectively) and across LSE types $(\mathrm{F}=8.89$ and $7.80, p=0.0001$ and 0.0006 respectively).

The dendrogram prepared from Bray-Curtis similarity between bird species composition across seasons (Fig. 4A) depicts mainly two clades one comprising of spring, summer and early winter and the other comprising of early monsoon, late monsoon and late winter. The dendrogram prepared from bird species composition across LSE types (Fig. 4B) shows close similarity between disturbed LSE types LSE 2, 4 and 5, which are relatively less similar to LSE 1 and 3 .

Community structure of the birds was dominated by insectivorous species (44\%). Birds with mixed diet consisting of fruits as well as insects were the next ones contributing $13 \%$ of the total avifauna, while frugivorous birds contributed $12 \%$ with almost the same dominance as the mixed diet birds (Fig. 5). Community structure analysis on the basis of breeding and non-breeding species revealed that all the seasons except early and late winter showed dominance of breeding species where as the community was dominated by non-breeding species in winter (Fig. 6).

Venn diagrams (Fig. 7) presenting the species diversity and distribution across three LSE types, which are subject to anthropogenic activities, revealed that there are seasonal changes in the species overlap patterns and the $\beta$ diversity varies a lot. However, there was no discrete trend observed for these changes. Spring, summer and early monsoon showed species overlap across all different LSE types considered in this comparative study. Though the overall pattern remained the same, the number of overlapping species as well as the component species in the overlap varied to a greater extent. Other seasons, however, showed distinctly different species overlap patterns especially between LSE 2 and LSE 5 .

\section{Discussions}

The seasonal distribution pattern showed two peaks of species richness and Shannon diversity index, one in spring and the other in early winter (Table 3). A number of reasons, including north-south migration, breeding, food availability and vegetation changes, could be attributed to this pattern. We suspect that a few of the migrants visit Tamhini during their north-south migration within Indian subcontinent, which contributes to high species richness during early winter. Also, as at the end of the winter these species migrate back towards north, the species richness in spring shows another peak. Breeding pattern can have a major influence on the distribution pattern. Depending on seasonality, many species breed in late winter, which contributes to more of nesting and less of 

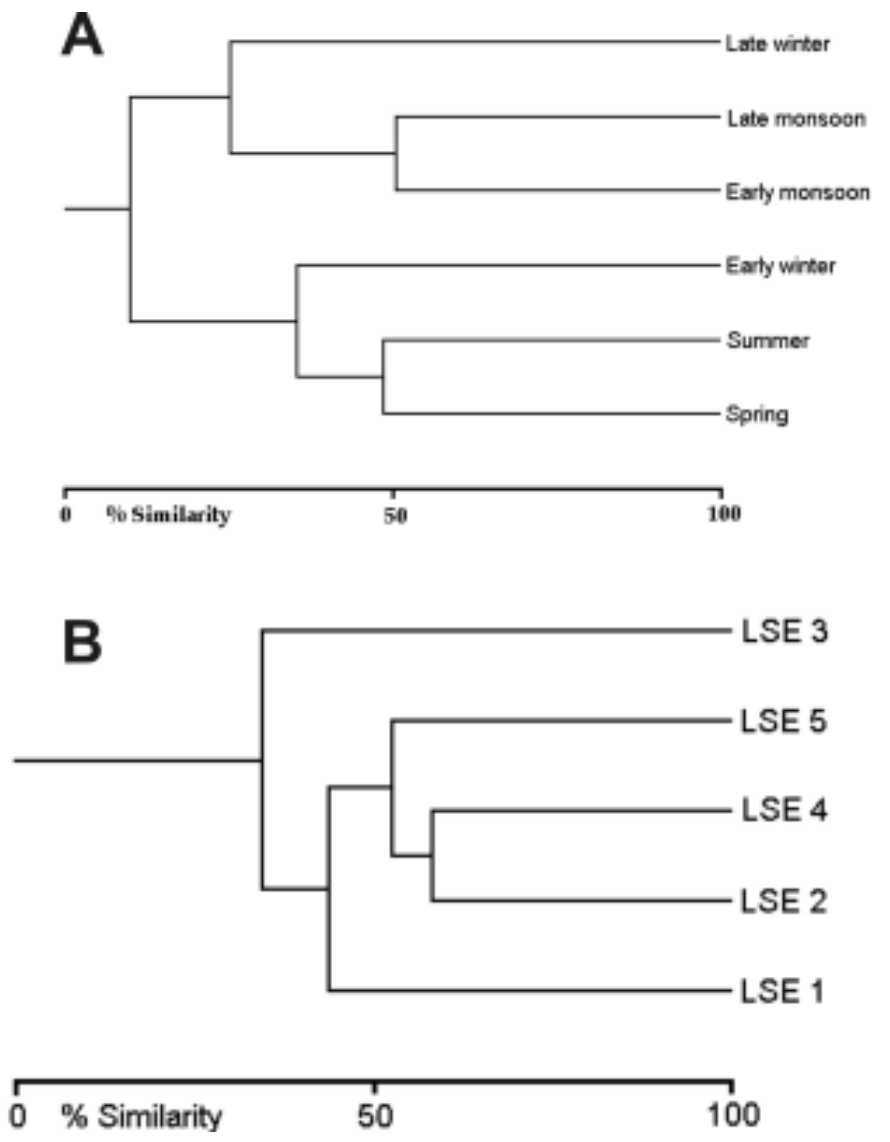

Figure 4. Dendrograms showing similarity in composition of avifauna across various seasons $(A)$ and across various LSE types (B)

roaming in late winter and hence low sighting. On the contrary, in spring probably eggs hatch and birds can be seen roaming as they gather food for the new born. New individuals can also contribute to high richness and diversity of spring. Paddy flowering in the early winter assures food availability and it could also be an important cause for high species richness, while comparatively low vegetation thickness in spring and summer can also contribute to high species richness and diversity mainly due to the fact that as there is more exposure, birds can be easily sighted. Low sighting of birds in monsoon could be due to the less activity.

Seasonal changes in the bird community in the foothills of Himalaya were studied by Sharma \& Mahabal (1997). There observations revealed that ecological conditions like climate, altitude and associated forest biotopes not only change the distribution pattern of birds but also change their seasonal abundance. However, in contrast to our studies, their study is purely qualitative without any statistical analysis supporting their observations.

Landscape element wise distribution pattern of birds showed high species richness and Shannon diversity in LSE 2, which comprise of Ragi shift cultivation - scrubland subjected to slash and burn activity followed by LSE 4 and LSE 5 , which comprise of grassland and human habitation, paddy fields and

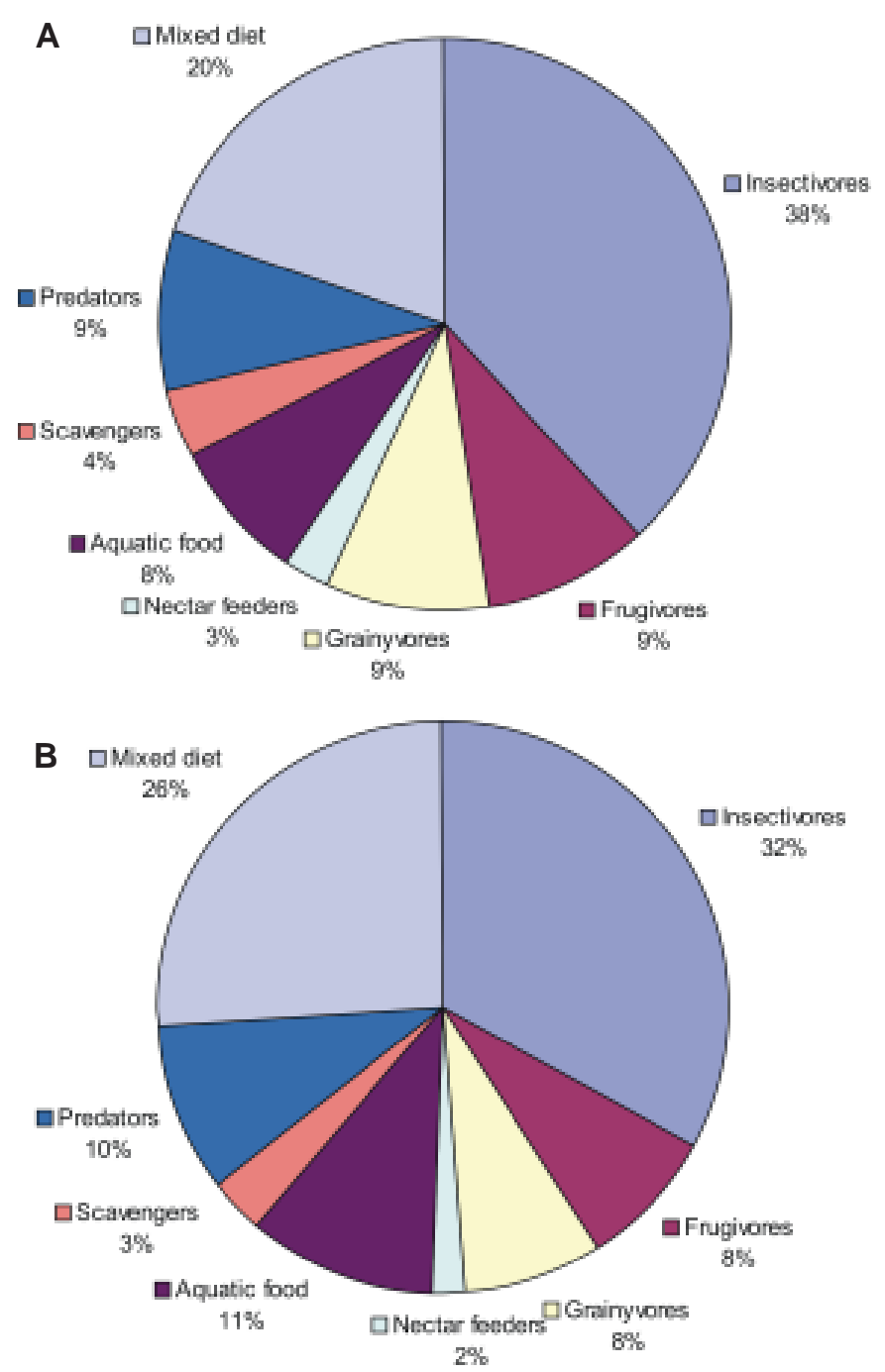

Figure 5. Community structure of the avifauna of Tamhini, based on the transect data $(A)$ and based on total checklist $(B)$. Note the dominance of insectivorous birds

scrubland, respectively; while there was less richness and diversity in LSE 1 and LSE 3, which comprise of evergreen forest, stream bank and grassland.

This indicates that there was more richness and diversity in the disturbed habitats rather than undisturbed habitats. Our observations support similar observations in prior studies in other regions of Western Ghats by Daniels et al. (1990) and Pramod et al. (1997a). However, according to Daniels et al. (1990), though there is an apparent increase in bird diversity of the man modified vegetation types, bird species composition is gradually changed from the typical one of the evergreen forest to that of more urban and scrubby habitats.

High diversity in the disturbed LSE types of our study area could be due to the diversity of niches that are present in LSE 2, 4 and 5. Paddy flowering is a major source of food for birds as well as insects. This also may be responsible for the increase in the population of grainivores, nectar feeders as well as insect eating birds during paddy flowering in LSE 2 and 5 . 
The community structure studies depict that there are seasonal changes in the community structure of the avifauna of our study area. Moreover, the changes appear to be cyclic throughout the year. Both $\alpha$ and $\beta$ diversity varies across the seasons to result into these seasonal changes. Species composition studies reveal that in our study area there are four major events that govern the diversity and distribution of avifauna and hence the changes in community structure across the seasons during the year.

a. Heavy rainfall resulting into west-east migration

b. Availability of food

c. Breeding season and

d. North-south winter migration

As the study area lies within the crestline parts of the Western Ghats, it receives heavy rainfall (as much as $4000 \mathrm{~mm}$ average annual rainfall). This is a major decisive factor. It results into a hostile environment for the birds to stay. The daylight is very poor; moreover the entire area is occupied by clouds resulting into poor visibility. Chilling winds worsen the wet conditions. This results into west-east migration of majority of the bird species during monsoon period. The birds from this part of the Western Ghats migrate eastwards in the less rainfall areas where the conditions are much better. This phenomenon was observed at many other places in the Western Ghats (Satish Pande, pers. comm.), however, a statistical analysis to support this observation is given in this study. In addition it appears from Fig. 7 that some species also change their habitat preference during the monsoon and either enter the other LSE types or restrict themselves to certain specific LSE types (e.g. LGB and PS). Thus, both west-east migration as well as local change in distribution could be the reason why species overlap pattern gets disturbed during the monsoon period (Fig 7). It is also possible that lower diversity found in the late monsoon owes to our limitations in sampling the avifauna due to such hostile conditions.

The species that still remain in the study area are habitat specific species, which can tolerate these hostile conditions. Moreover, some species are known to change their behaviour and become secretive to reside in the dense canopy (Satish Pande, pers. comm.) and thus can not be encountered during the transects. Most of the species encountered in transects during monsoon breed in this season. The early and late monsoon community, therefore, consists of more than $50 \%$ of breeding species (Fig. 6).

These conditions also result into less food availability. As it is evident from Fig. 5, frugivorous and insectivorous birds $(69 \%)$ constitute majority of the bird community in our study area. Therefore the food availability for these birds is extremely poor during the monsoon season. This is another reason for their migration towards eastern parts.

Subsequent seasons show better food availability due to increasing sunlight and temperatures as well as reduction in rainfall. Insect population rises from October onwards and hence the birds start coming back. The species overlap pattern starts getting restored.

High $\alpha$ - and $\beta$-diversity during spring and summer is attributed to the availability of diverse food. Majority of the flora of our study area shows flowering / fruiting during this

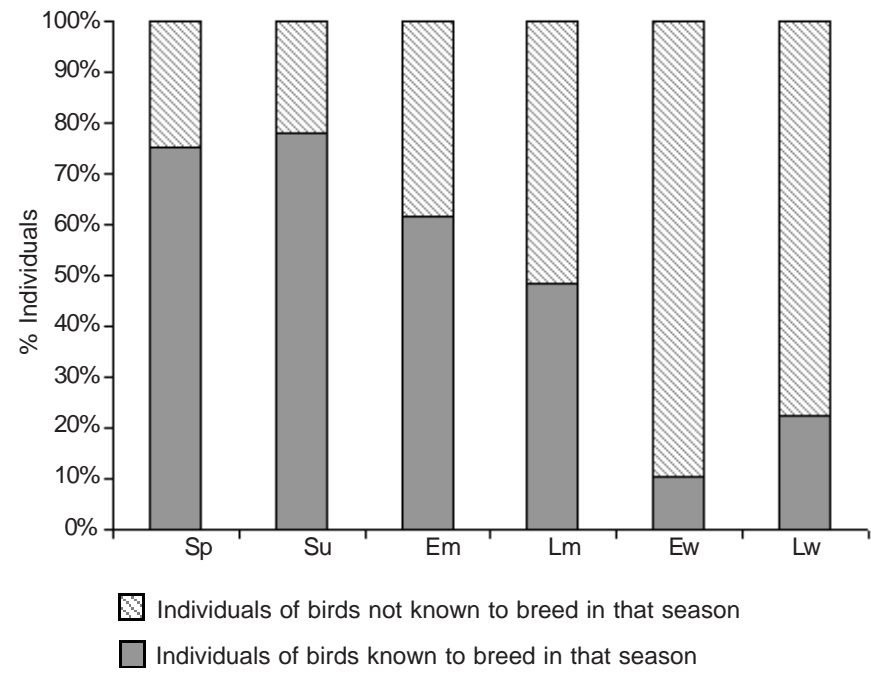

Figure 6. Percentage abundance of breeding and nonbreeding birds in six seasons

period. The insect population is also at its top due to favourable climatic conditions. Increase in population of other birds also favours the birds of prey that feed on these small birds. In fact these are the seasons for breeding of most of the birds of prey. Such conditions also favour breeding of most other bird species encountered in transects. Therefore more than $75 \%$ breeding species contribute to the community structure during these seasons (Fig. 6).

The winter community is heavily dominated by nonbreeding species, which contribute to more than $75 \%$ of birds (Fig. 6). As most of the birds of our study area breed during the spring, summer or monsoon period, their young ones appear in flight during winter and spring. Also migratory birds visit our study area during winter. This also contributes to the increased $\alpha$ diversity (Table 3) and $\beta$-diversity (Fig. 7) of our study area during late winter and spring.

North-south migration of winter visiting birds shows a typical feature. It appears from our data that north-south migrating birds might be using our study area as a transit place and do not wait for longer time as they migrate further southwards. However, while returning, they halt in our study area for a longer time. This could be the reason why many of them were not encountered in the transects during the early winter period as in contrast with the spring and summer, wherein most of them were noticed in the transects. The raised $\alpha$ and $\beta$ diversity of spring and summer is also due to this reason.

A complex bird community in the study area is evident of combination of all these factors. Our study area is a representative of northern Western Ghats. Overall geographic and climatic conditions of our study area match with any other part of the northern Western Ghats. Moreover, the human interfered landscape elements (similar to LSE 2, 4 and 5 of our study area) are more common in this region as well as the remaining parts of the Western Ghats.

As per the earlier studies (Gole, 1998), moist deciduous and semievergreen forests between $620 \mathrm{~m}$ and $920 \mathrm{~m}$, in the northern Western Ghats, are the best habitats for the birds as far as the 

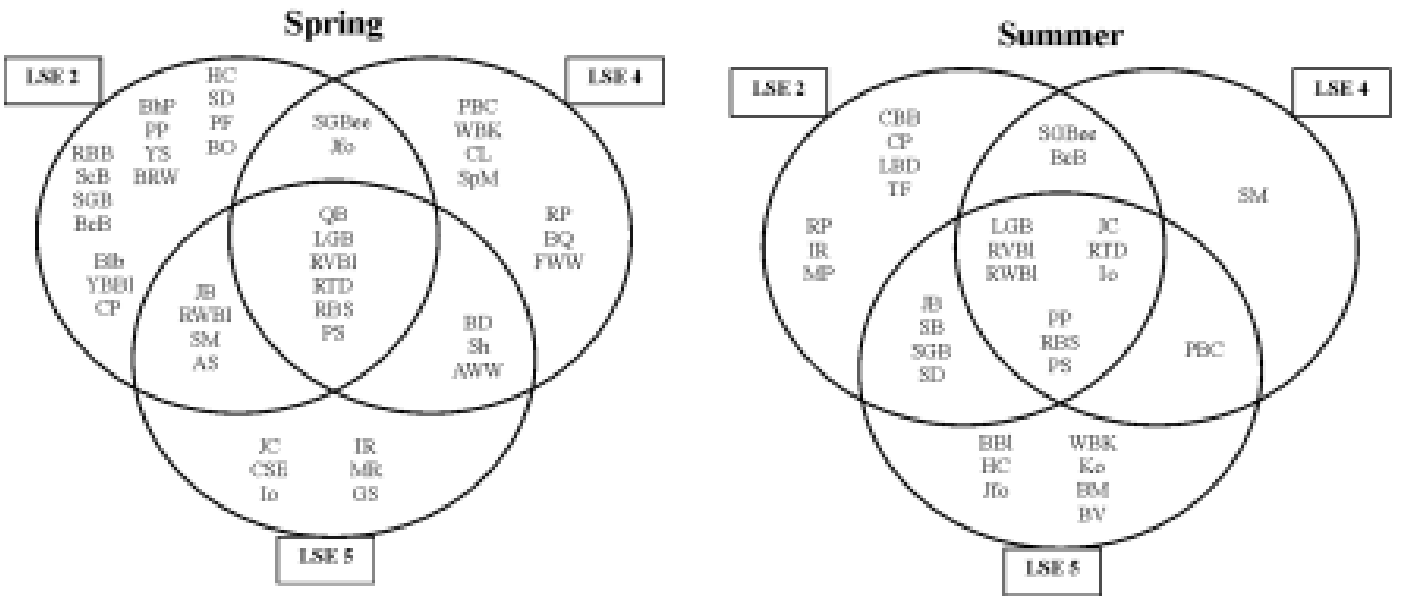

Early Monsoon

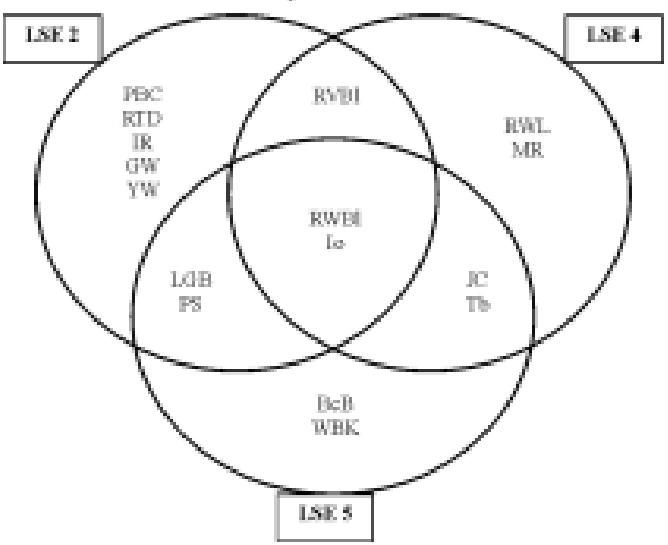

Late Monsoon
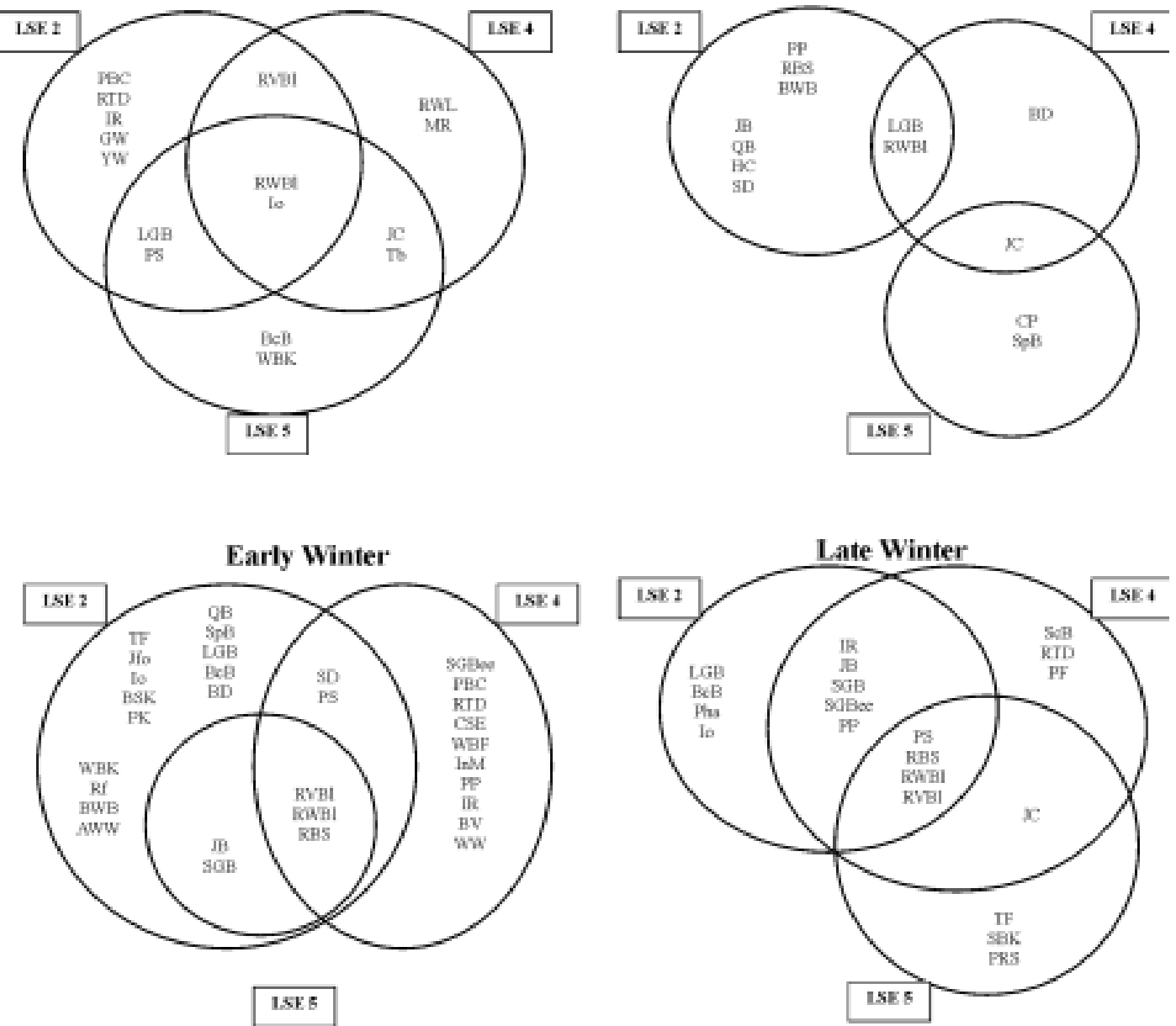

Figure 7. Venn diagrams depicting the dynamics of avifaunal population changes (This is a diagrammatic representation)

Abbreviations for bird names are: AS - Alpine Swift; AWW - Ashy Prinia; BBI - Black Bulbul; BcB - Eurasian Blackbird; BD - Black Drongo; BhP - Plum-headed Parakeet; Blb - Asian Fairy Bluebird; BM - Brahminy Starling; BO - Blacknaped Oriole; BQ - Common Bush Quail; BRW - Blyth's Reed Warbler; BSK - Storkbilled Kingfisher; BV - Long-billed Vulture; BWB - Baya Weaver; CBB - Coppersmith Barbet; CL - Malabar Crested Lark; CP - Greater Coucal; CSE - Creasted Serpent Eagle; FWW - Franklin's Prinia; GS - Southern Grey Shrike; GW - Grey Wagtail; HC - House Crow; InM - Common Myna; Io - Common Iora; IR - Indian Robin; JB - Jungle Babbler; JC - Jungle Crow; Jfo - Grey Junglefowl; Ko - Asian Koel; LBD - Little Brown Dove; LGB - Brown-headed Barbet; MR - Oriental Magpie Robin; PBC - Pied Bushchat; PF - Asian Paradise Flycatcher; Pha - Montagu's Harrier; PK - Lesser Pied Kingfisher; PP - Painted Francolin; PRS - Purple-rumped Sunbird; PS - Purple Sunbird; OB - Quaker Babbler; RBB - Rufus Bellied Babbler; RBS - Rufus-backed Shrike; Rf - Common Rose finch; RP - Rose-ringed Parakeet; RTD - Red Turtle Dove; RVBI - Red-vented Bulbul; RWBI - Red-whiskered Bulbul; RWL - Red-wattled Lapwing; SBK - Small Blue Kingfisher; ScB - Slatyheaded Scimitar Babbler; SD - Spotted Dove; SGB - White-cheeked Barbet; SGBee - Small Green Bee-eater; Sh - Shikra; SM - Scarlet Minivet; SpB - Spotted Babbler; SpM - Spotted Munia; Tb - Common Tailor Bird; TF - Tickell's Flowerpecker; WBF - White-bellied Blue Flycatcher; WBK - White-breasted Kingfisher; WW - White Wagtail; YBB - Yellow-browed Bulbul; YS - Small Sunbird; YW - Yellow Wagtail. 
number and diversity is concerned. However, the canopy forest in this area is declining very fast, threatening the existence of many bird species including the endemic ones, a globally serious problem. As the most serious loss of the biodiversity value arises in the transformation of original landscapes due to human interference (Pramod et al., 1997b), evaluation of bird communities from various study sites from the Western Ghats is essential for planning "biodiversity-friendly" development.

In accordance to similar studies from this study area on amphibians (Dahanukar \& Padhye, 2005) and butterflies (Padhye et al., 2006), the results of our study on the avifauna can be used for conservation prioritisation and management of the biodiversity of the northern Western Ghats.

\section{REFERENCES}

Ali, S. (1996). The Book of Indian Birds. $12^{\text {th }}$ edition. Bombay Natural History Society, Oxford University Press, Mumbai, 354pp.

Dahanukar, N. \& A. Padhye (2005). Amphibian diversity and distribution in Tamhini, northern Western Ghats, India. Current Science 88: 1496-1501.

Daniels, R.J.R., M. Hegde \& M. Gadgil (1990). Birds of the man-made ecosystems: the plantations. Proceedings of the Indian Academy of Science (Animal Science) 99: 79-89.

Daniels, R.J.R., N.V. Joshi \& M. Gadgil (1992). On the relationship between bird and woody plant species diversity in the Uttara Kannada district of south India. Proceedings of the National Academy of Science USA 89: 5311-5315.

Gadgil, M. (1996). Documenting diversity: an experiment. Current Science 70: 36-44.

Gole, P. (1998). Birds of the Sahyadri. Journal of Ecological Society 11: 5-28. Jha, C.S., C.B.S. Dutt \& K.S. Bawa (2000). Deforestation and land use changes in Western Ghats, India. Current Science 79: 231 - 238.

Magurran, A.E. (1988). Ecological diversity and its measurement. Chapman and Hall, London, 168 pp.

Manakadan, R. \& A. Pittie (2002). Standardised common and scientific names of the birds of the Indian subcontinent. Newesletter for Birdwatchers 42: 1-36.

McAleece, N. (1998). BioDiversity Professional Beta. The Natural History Museum and The Scotish Association for Marine Sciences.

Mittermeier, R.A., N. Myers, J.B. Thomsen, G.A.B. da Fonesca \& S. Oliveri (1998). Biodiversity hotspots and major tropical wilderness areas: approaches to setting conservation priorities. Conservation Biology 12: 516-520.

Myers, N. (1990). The Biodiversity challenge: expanded Hot Spots analysis. Environmentalist 10: 243-256.

Myers, N., R.A. Mittermeier, C.G. Mittermeier, G.A.B. da Fonesca \& J. Kent (2000). Biodiversity hotspots for conservation priorities. Nature 403: 853-858. Padhye, A.D., N. Dahanukar, M. Paingankar, M. Deshpande \& D. Deshpande (2006). Seasonal and landscape wise distribution of butterflies in Tamhini, northern Western Ghats, India. Zoos' Print Journal 21: 2175-2181.

Pande, S. (2003). Birds of Western Ghats, Kokan and Malabar (Including Birds of Goa). Bombay Natural History Society, Mumbai and Oxford University Press, New Delhi, 377pp.

Paranjape, S.A. \& A.P. Gore (1997). Effort needed to measure biodiversity. International Journal of Ecology and Environmental Sciences 23: 173-183.

Pramod, P., N.V. Joshi, U. Ghate \& M. Gadgil (1997a). On the hospitability of Western Ghats habitats for bird communities. Current Science 73: 122-127.

Pramod, P., R.J.R. Daniels, N.V. Joshi \& M. Gadgil (1997b). Evaluating bird communities of Western Ghats to plan for a biodiversity friendly development. Current Science 73: 156-162.

Sechrest, W., T.M. Brooks, G.A.B. da Fonseca, W.R. Konstant, R.A. Mittermeier, A. Purvis, A.B. Rylands \& J.L. Gittleman (2002). Hotspots and the conservation of evolutionary history. Proceedings of the National Academy of Science USA 99: 2067-2071

Sharma, T.R. \& A. Mahabal (1997). Seasonal changes of birds in two different altitudinal locations of solan district, Himachal Pradesh. Records of the Zoological Survey of India 96: 151-165.

\section{GOV ND BAШABH PANTINSTITUTE OF HIMALAYANENM RONMENT ANDDEVELOPMENT}

(An Autonomous Institute of Ministry of Environment \& Forests, Government of India) Kosi-Katarmal, Almora 263 643, Uttarakhand, India

G.B. Pant Institute of Himalayan Environment and Development is one of the premier autonomous Institutes of the Ministry of Environment and Forests, Government of India. The Institute invites applications for the following completely temporary project position for its North-East Unit. Qualified candidates may send their duly filled in application super-scribed as "Application for the Post of JRF" along with copies of certificates, testimonials, biodata within twenty days from the date of circulation/publication of this advertisement to Scientist In-charge, G.B. Pant Institute of Himalayan Environment and Development, NE Unit, Vivek Vihar, I tanagar 791 113, Arunachal Pradesh.

\section{Project:}

Shifting agriculture: issues and options with focus on adaptive interventions to make it ecologically, economically and socially viable.

\section{J unior Research Fellow (1):}

Pay: RS. 8000/- pm (+HRA as per institute rules); Age: not more than 28 years.

Qualification: Masters degree in Wildlife/Zoology/ Ecological/Life sciences or any subject relevant to Wildlife Sciences from a recognized University with first division and consistently good academic record.

Desirable: Interest and skills in bird and mammal identification; field experience in monitoring animals/ habitats; experience in field based wildlife/conservation research projects will be given preference.

Experience of working in north-eastern region and knowledge of local languages. Good knowledge of computer operation and statistical analysis. Relaxation in age as per rule for $\mathrm{SC} / \mathrm{ST} / \mathrm{OBC} /$ women candidates. Work involves extensive touring and field data collection in remote areas across Arunachal Pradesh and demonstrating / disseminative activities of the Unit. Please note that no TA/DA will be given to the short-listed candidates appearing for the interview. The appointment shall be, initially, for a period of one year and extendable on year to year basis depending on the performance and evaluation to be carried out on regular intervals. The appointment could be terminated anytime. Selection shall not confer any right of regular appointment in the Institute. Advance copy of applications could be sent via email to: neunit@gmail.com or gbpihedne@yahoo.co.in 